\title{
Understanding Country Differences: Predicting the Effect of Financial and Labor Market Conditions on International Doctoral Recipients' First Labor Market Destination
}

\author{
Osasohan Agbonlahor \\ University of Colorado - Colorado Springs, USA \\ Frim Ampaw \\ Central Michigan University, USA
}

\begin{abstract}
This study used the Survey of Earned Doctorates, World Bank economic data of the doctoral students' home country, and hierarchical linear modeling analysis to examine the effects of financial factors and home-country macroeconomic indicators on international doctoral students' labor market destinations. We found that wealth disparities and economic opportunities in the home country affect international doctoral student outcomes. Higher gross national income per capita was associated with decreased likelihood of remaining in the United States, while higher unemployment rates in the home country significantly increased the likelihood of remaining in the United States. The study reveals a need to develop career services support for international doctoral students that are tailored to their needs as well as the need to internationalize the curriculum to support those who will eventually return to their home country.
\end{abstract}

Keywords: economic opportunities, international doctoral recipients, labor market outcome 


\section{INTRODUCTION}

While experiences of international students in the United States have been discussed in the literature, research analyzing their transition into the labor market is relatively limited. However, the existing research suggests a low transition rate into the U.S. labor market, mainly due to the limited availability of work visas (Migration Policy Institute, 2018). There is some empirical evidence that shows the benefits of the immigration of high-skilled workers for the U.S. economy. Bound et al. (2017) constructed a general equilibrium model of the U.S. economy and calibrated it using data from 1994 to 2010 . They found that in the absence of immigration, wages for U.S. computer scientists would have been $2.6 \%$ to $5.1 \%$ higher, and employment in computer science for U.S. workers would have been $6.1 \%-10.8 \%$ higher in 2010 . However, complements in production benefited substantially from immigration, and immigration also lowered prices and raised the output of information technology goods by $1.9 \%-2.5 \%$, thus benefiting U.S. consumers.

Different studies have produced different results on who plans to transition into the U.S. job market, likely because they have been conducted at different periods when macroeconomic conditions of the home country might have significantly changed. In one of the earliest studies of student migration to the United States, Das (1969) found "a very small proportion of the African and Latin American students wish to remain here permanently. It is, students from the developed countries, who plan to stay in this country" (p. 130). However, later analysis identified those from less developed countries as more likely to stay (Finn, 2001; Glaser, 1978). Similarly, Finn (2001) found that 71\% of international doctoral graduates in the science and engineering fields who received their degrees in 1999 were still in the United States in 2001. The research studies discussed above have limitations that may hinder our understanding of the factors impacting the labor market choices of international doctoral students. Most of these studies have not focused on the international doctoral student and the unique macroeconomic conditions in their home countries that could impact the outcome.

The studies on migratory decision making (e.g., Szelenyi, 2012) have used qualitative data to understand international student labor market decision making processes. However, the qualitative data is limited to very few countries and the experiences of very few individuals, which cannot be considered representative of the population. The studies that have used quantitative data (e.g., Das, 1969; Finn, 2001) are outdated and have relied on Immigration and Naturalization Service Data to reflect adjustment from nonimmigrant to immigrant status of international students. These data do not contain the rich attributes of Survey of Earned Doctorates, including the students' prior academic background and postgraduation plans. This study utilizes a conceptual model based on human capital theory and the push-pull model of international education flows, which presumes that the international doctoral student's labor market destination is a function of gender, country of citizenship, expected costs and benefits, and economic indicators in the home and host country. 


\section{Purpose of the Study}

The purpose of this study is to examine the effects of financial aid and homecountry macroeconomic indicators on international students' labor market destination choices. Hence, this study employed a nonexperimental research design using secondary data from the Survey of Earned Doctorates (SED) and economic data of the students' home country in addressing the following research questions:

1. What is the effect of demographic characteristics, financial aid packages, home-country economic factors, and institutional level variables on the location of the first job of international doctoral recipients?

2. Do international doctoral recipients differ in their labor market destination choices by region and classification of income of their home countries?

\section{THEORETICAL FRAMEWORK}

The conceptual framework for this research utilized the human capital theory and the push-pull model of international education flows. Human capital theory lends itself to the explanation of the decision-making process of international doctoral students. International doctoral students forgo wages and invest more in their foreign education with the hopes of gaining both intrinsic and extrinsic benefits. Extrinsic benefits from education include the higher expected future earnings as a result of their education and subsequent economic opportunities (Acemoglu et al., 2015; Becker, 1962). The extrinsic costs of foreign doctoral education include the tuition and fees paid to attain the education, plus the opportunity costs, which are the earnings the student forfeited upon undertaking full-time education. Financial aid subsidizes extrinsic costs, but the type and nature of funding could have an impact on the labor market destination outcomes for the student. For example, students receiving funding from their home country government or foreign fellowships or grants may be more likely to choose to return to their home countries upon graduation.

The conceptual model includes demographic characteristics, which can also be examined within the human capital theory opportunity cost framework. The opportunity cost includes the psychological costs of leaving friends and family, adjusting to the U.S. job market, and the time spent in efforts to attain $\mathrm{H}-1 \mathrm{~B}$ employment rather than returning home. Societal norms place primary care responsibility on women, and thus, married women with dependents may choose to remain where their spouses are after graduation. Academic discipline is included in the model because their fields have research norms and standards that impact career choices. Also, with H-1B immigration laws, which favor those in the science, technology, engineering, and mathematics (STEM) fields to fill the demand for such skills in the United States' labor market, international students in those fields may be more likely to transition into the U.S. market than their 
non-STEM doctoral degree counterparts. Prior U.S. educational experience is also included in the framework because those who have spent a long time in the United States before beginning the doctorate will have invested more in their U.S. education, and may also have built more friendships and relationships, making them less likely to return home.

Human capital theory assumes opportunity costs affect student decisions that impact on their choices, but it does not explicitly consider macroeconomic conditions from the home country. The second part of the conceptual framework is based on the push-pull model of international education flows. Mazzarol and Soutar (2002) based the model on the decision process undertaken by an international student when choosing a study destination. In the first stage, the student decides to study abroad rather than in their home country. Several push factors influence this. Push factors refer to considerations within the home country such as the level of economic wealth, the degree of involvement of the developing country in the world economy, the priority placed on education by the government, and availability of educational opportunities in the home country that usually work together to push students to seek education internationally. These same factors will influence the student's decision to return home or remain in the host country. International doctoral students from low-income countries are more likely to be pushed out by harsher economic conditions in their country to search for greener pastures. In stage two, pull factors become crucial and determine why one country is preferred to another. Pull factors include the opportunities for employment during and after graduation, and the relative prosperity of the host country compared with the home country. Students from wealthier and more developed countries with lower unemployment rates and more opportunities for upward mobility are more likely to return home. The type of funding, the amount of time the student spends in the host country, and the relationships developed within the time spent studying in the United States will determine their labor market destination choices. For this study, we use this process to help understand the decision to exit or stay in a foreign country after the period of study.

The fundamental assumptions are that the more disadvantaged a country is, the more likely its citizens will seek opportunity outside its shores and that, given inequalities, there will be migration. That is, international students from countries with more economic, social, and political hardships are more likely to remain in the United States after graduation because of limited opportunities in the home country. For international students from poorer countries, these benefits will also include access to job opportunities in the host country and possibly higher earnings than what they would earn with the same degree at home because of international job market imperfections. Students from high-income countries and upper-middle income economies will gain higher intrinsic and extrinsic benefits from returning to their home countries.

While the push-pull model of education flows focuses more on the decision to embark on international doctoral studies rather than the decision to stay or return home after obtaining the doctoral degree, implicit in this model is that several negative or push factors in the country-of-origin cause people to move away, in combination with other positive or pull factors that attract migrants to a 
receiving country. The general criticism is that such models do not explain why within regions some people move and others stay, nor can they explain the direction of flows.

The neoclassical macroeconomic theory explains the development of labor migration within the process of economic development (Todaro, 1976). Wage differentials, caused by differences in the ratio of labor to capital, induce workers from low-wage countries to migrate to countries with high wages, thereby seeking to maximize individual incomes (Todaro, 1976). Migration causes wage differentials to decrease, ultimately leading to an equilibrium in which the remaining wage differential only reflects the costs of moving (Massey et al., 1993). In this type of model that focuses completely on labor markets, wage differentials measured in terms of observed wage rates at the origin and the destination are the main explanatory variables (Massey et al., 1993).

On the other hand, neoclassical microeconomic models assume that individuals make rational cost-benefit calculations. Assuming the benefits of expected higher wages are a function of wage differentials and employment rates, there are implied costs. Such costs include those related to travel, wages foregone while looking for work, efforts involved in adapting to another country, and the psychological costs of leaving friends and family (Todaro, 1976). Individual characteristics explain why individual cost-benefit calculations produce different outcomes concerning the decision to migrate. In general, the larger the difference between countries in terms of expected returns, the larger the size of the migration flow.

\section{LITERATURE REVIEW}

International graduate students' decisions regarding return to their home countries, remaining in the host society, or relocating to a third country are closely related to the literature on brain migration. The literature on international highly skilled migration has undergone significant changes since the 1960s. On one side of the argument is the notion of human capital transfers, with industrialized countries benefiting, while developing nations suffer significant losses in economic and educational development, as a result of the departure of their more educated citizens (Bhagwati \& Dellalfar, 1973; Haque \& Kim, 1995). There have been some studies on international students within the European Union given the open borders (Bryla, 2019; Sage et al., 2013). These studies have focused on all students and show that doctoral students were more likely to take jobs outside of their home country (Bryla, 2019).

In Johnson and Regets' (1998) study of foreign-born science and engineering graduate students earning doctoral degrees between 1988 and 1996, 63\% of all students had plans to remain in the United States, while an additional $39 \%$ had firm plans to stay, indicating they had received firm offers to engage in postdoctoral research, gain employment, pursue teaching, or participate in other activities in the United States. (Johnson \& Regets, 1998). In this study, while $47.9 \%$ of Chinese and $54.7 \%$ of Indian students indicated firm plans, only $22.6 \%$ of South Korean and $27.5 \%$ of Taiwanese students did so. 
Desjardins (2012) sought to better understand the profile and labor market outcomes of recent doctoral graduates from Ontario universities who lived in Canada or the United States after 2 years of graduation. The results from the study revealed that at the time of graduation, $78 \%$ of the graduates had firm postgraduation plans, with $21 \%$ intending to leave Canada for the United States. Most who planned to move to the United States (62\%) were young males with no dependents who studied life sciences, computer science, mathematics, or physical sciences, which reflects the demand and higher wages for such skills in the United States. Among the factors identified to attract Canadian doctoral graduates to the United States were: (a) the quality of the research facilities or the commitment to research of the organization; (b) better career advancement opportunities; (c) a greater availability of jobs in a particular field or industry; (d) a higher salary; (e) the quality of the research facilities or the commitment to research; and (f) the greater availability of jobs.

Szelenyi (2006) suggested that the less-developed a country is, the more elites of the country choose to pursue education and careers in other countries. According to Szelenyi (2006),

This is not the case with nationals from the more highly developed countries, where mobility opportunities are more broadly shared and where people who move internationally have made much more marginal, risky, career decisions compared to those in nationalized careers from welfare-states with stable pay-offs at home. (p. 10)

Szelenyi (2006) used semi structured interviews and 26 international graduate students (Brazilian, Chinese, and Italian) who were enrolled in a U.S. Western institution in the 2003-2004 academic year to understand migratory decision-making. The author stated that:

While the students presented a wide variety of experiences, intentions, and views, the transformational power of education abroad, within that diversity, was evident in redrawing students' conceptions of national boundaries and their own positions in relation to those boundaries. The students expressed a clear sense of national borders in their aspirations; the dilemma between returning to their home countries and staying within the geographical boundaries of the U.S., for example, was a major force shaping their plans for the future. (p. 84)

It is important to understand how economic conditions in the home country, in addition to individual and field variables, affect labor market choices of international doctoral students. This knowledge can guide career services on the U.S. campus, faculty advisors, and international advisors in better serving these students' career needs. In developing and implementing services to meet the needs of international doctoral students, Yang et al. (2002) identified the following ways that university career services can better meet the needs of international students: (a) Career services need to be responsive to the cultural contexts of the international students being served. (b) The services and interventions need to be provided through a cultural lens and not assumed that services designed for U.S. 
students will necessarily meet the needs of international students. (c) More assessment tools and strategies that are culturally valid for diverse groups of international students need to be developed. (d) Having resources on career opportunities and employment-related information from other countries available is very important.

International graduate students are highly concerned about job placement because successful job placement may enable them to transition into the U.S. labor force and earn higher incomes than in their home countries (Hazen \& Alberts, 2006). This may be particularly true for those from poorer countries. Advisors among the international student population are valued when they support conference attendance and co-authorship, refer job opportunities, and offer career advising. The findings in this study identify factors that affect the international doctoral recipients' choices across regions and field.

\section{METHOD}

\section{Data Sources}

We used the Survey of Earned Doctorates (SED) as the main source of data for our research. The SED is a nationally prepared, institutionally administered survey of all doctorate recipients in the United States. The survey is conducted annually for all doctorate recipients between the period July 1 and June 30 of the following year. We used an analytical sample of all international students who held a foreign visa during their time of study and who graduated between the period of 2011-2016. The institutional information (Carnegie classification) came from the National Center for Educational Statistics (NCES) Integrated Postsecondary Education Data System (IPEDS). We also used World Bank data, which provides the home country macroeconomic variables such as gross national income (GNI) per capita, wages, and unemployment rates of advanced degree holders. Data from the World Bank is for 2010-2015, which captures how macroeconomic conditions in the home countries of doctoral recipients impacted their labor market choices. Finally, this study uses data from the National Faculty Salary Survey, which provides information on the median U.S. assistant professor salary in different fields as a proxy for expected earnings.

\section{Variables}

The dependent variable reflects the students' labor market destination choice. In the SED, doctoral recipients are asked, "In what country or state do you intend to live after graduation? Please indicate the geographic location where you will work or study?" This variable reports the location (the United States or NonUnited States) where the doctorate recipient will live, work, or study after graduation. In this study, the location of the first job (U.S. job) was coded as 0 (no) and 1 (yes). The independent variables that predicted these binary outcomes are categorized into five groups: student background characteristics, academic experiences, financial sources, external responsibilities, and economic conditions. 
Student background characteristics include gender, nationality (with European students being the reference group for the first analysis and high-income countries being the reference in the second analysis), age, and parental education. Following the World Bank's (2017) categorization, we classified citizenship into six broad categories - North Africa, Sub-Saharan Africa, South East Asia, East Asia, Middle East, and Europe and Australia. We then conducted analyses by region and income classification. We determined first-generation status by using a combination of the mother's and father's levels of education. If neither parent attained a bachelor's degree, the student was considered a first-generation college student. If at least one of the parents attained a bachelor's degree or higher, we placed the student in the continuing generation category.

Prior educational experiences included whether the student received a bachelor's or master's degree from the United States. Doctoral students vary in the number of family responsibilities they hold during their pursuit of the degree. The predictor variables in this category included indicator variables of marital status and dependents. All three variables were dummy coded and included in the analysis. Employer type is a dichotomous variable representing the recipients either choosing or having obtained employment in a university/college or the industry/other type of employment (such as the military).

Financial aid variables include loans, assistantships, U.S. awarded grants and fellowships, and scholarships from the home country. Research, teaching assistantships, fellowships, and foreign sources were dummy coded. Loans for undergraduate and graduate education were combined and grouped into three categories based on frequency distribution - no debt, debt of $\$ 20,000$ or less, and debt of $\$ 20,0001$ or more.

The institutional level variable that is associated with labor market outcome is Carnegie classification. Carnegie classification is a dichotomous variable that refers to whether the institution is research extensive or research intensive. We also included the field of study to control for any unobserved effects. We coded the field of study into seven categories: biological sciences, engineering, physical sciences, social sciences, humanities, education, and business.

The push factors include macroeconomic variables in the home country, which work to push the student to obtain a foreign in less time while simultaneously impacting the labor market choices of the student. These include the real GNI per capita, unemployment rates, and wages of professionals in the home country. Pull factors refer to economic conditions in the United States (in comparison with the economic conditions of the home country of the students), that work to pull the student into the U.S. labor market. The U.S. assistant professor's salary in each field is a proxy for the living conditions in the United States.

\section{Analytical Method}

We used both logistic regression and then a hierarchical linear model (HLM) to determine the effects at two levels (individual and country). We used logistic regression to answer the first research question. Logistic regression is appropriate 
for binary dependent variables and allows researchers to determine the best combination of variables that predict an outcome by estimating the probability of the dependent variable occurring as the values of the independent variables change. The outcome variable, labor market destination outcome, was regressed on the independent variables. Separate regressions were conducted for the different economies to sharpen our focus on country differences, which is a major aim of the study. The effect sizes of the variables on the labor market destination are shown using odds ratios (Thomas \& Heck, 2001).

Due to our interest in the effect of macroeconomic conditions of the home country, we conducted HLM to take advantage of the nesting structure of the data. We were able to then assess estimates of the effects of Level 2 variables (i.e., home country) more accurately on Level 1 outcome measures (Heck \& Thomas, 2000). The Level 1 equation in HLM analysis is as follows:

$$
\begin{gathered}
Y_{i k}=\beta_{0 j k}+\beta_{1 k}(\text { demographic variables })_{i k}+\beta_{2 k}(\text { finance variables })_{i j k} \\
+\beta_{3 k}(\text { institutional variables })_{i k}+e_{i k}
\end{gathered}
$$

where $i=$ individual student, $k=$ home country; $Y_{i k}$ represents the dependent variable (labor market outcome) for an individual observation of student $i$ from country $k ; \beta_{0 k}$ is the intercept of the dependent variable and country-level predictor; $\beta_{1 k}$ is the slope of variable $X_{1}$ from country $k$; and $e_{i}$ is the random error predicted for student $i$ from country $k$.

An important assumption of HLM is that any Level 1 errors $\left(r_{i j k}\right)$ follow a normal distribution with a mean of 0 and a variance of $\sigma^{2}$.

$$
\begin{aligned}
& E\left(r_{i k}\right)=0 ; \operatorname{var}\left(r_{i k}\right)=\sigma^{2} \\
& \beta_{0 k}=\Upsilon_{00}+\Upsilon_{01} w_{k}+\mu_{0 k}
\end{aligned}
$$

$\Upsilon_{00}$ is the overall intercept; $w_{k}$ is the country-level predictor; $\Upsilon_{01}$ is the slope between the dependent variable, and the country-level predictor; and $\mu_{0 k}$ is the random error component for the deviation of the intercept of a group from the overall intercept.

Treating missing data requires attention in HLM analysis (Wong \& Mason, 1995). The HLM model assumes the data files are complete and does not allow for missing data; thus, we deleted any observations with missing data.

\section{RESULTS}

Table 1 presents the descriptive statistics of the categorical variables. For the sample, about $23 \%$ of international students who graduated between the period of 2011-2016 chose to return to their home country or a foreign country for employment while $77 \%$ chose to work in the United States. Sixty-two percent of the students obtained their doctorate degrees in STEM fields: biological sciences (18\%), physical sciences (29\%), and engineering (25\%). Half of the students were 
from upper-middle income countries, followed by high-income countries $(25 \%)$, lower-middle income countries (22\%), and low-income countries (2.4\%). Almost half of the students were from East Asia and the Pacific, followed by South Asia (17.96\%), Europe and Central Asia (12.95\%), Middle East and North Africa (8.79\%), Latin America and the Caribbean (7.2\%), Sub-Saharan Africa (3.25\%), and North America (3.14\%). Sixty percent of the sample had a previous degree from the United States. The majority of students were supported by a research assistantship (47\%), and $83 \%$ of them indicated having secondary financial support in addition to their primary sources of funding.

Table 1: Descriptive Statistics for Categorical Variables

\begin{tabular}{lc}
\hline Variable & $\%$ \\
\hline Postgraduation location & \\
Outside the United States & 22.9 \\
United States & 77.1 \\
Gender & \\
Male & 62.7 \\
Female & 37.2 \\
Parents' education & \\
First generation & 38.2 \\
Bachelor's degree & 30.9 \\
Graduate school & 30.9 \\
Region & \\
Europe and Central Asia & 12.9 \\
East Asia and Pacific & 46.7 \\
Latin America \& the Caribbean & 7.2 \\
Middle East \& North Africa & 8.8 \\
North America & 3.1 \\
South America & 17.9 \\
Sub-Saharan Africa & 3.2 \\
Economy & \\
High income & 24.7 \\
Upper-middle income & 50.8 \\
Lower-middle income & 22.1 \\
Low income & 2.4 \\
Prior academic experience & \\
U.S. bachelors & \\
No & 91.2 \\
Yes & 8.8 \\
U.S. masters & \\
No & 40.2 \\
Yes & 59.0 \\
Academic discipline & 18.3 \\
Biological sciences & 29.3 \\
Engineering & 25.2 \\
\end{tabular}




\begin{tabular}{|c|c|}
\hline Variable & $\%$ \\
\hline Physical sciences & 11.2 \\
\hline Social sciences & 4.6 \\
\hline Humanities & 3.5 \\
\hline Education & 3.7 \\
\hline Business management & 4.0 \\
\hline \multicolumn{2}{|l|}{ Family/external responsibilities } \\
\hline \multicolumn{2}{|l|}{ Single } \\
\hline No & 56.6 \\
\hline Yes & 43.3 \\
\hline \multicolumn{2}{|l|}{ Dependents } \\
\hline No & 72.1 \\
\hline Yes & 27.9 \\
\hline \multicolumn{2}{|l|}{ Program characteristics } \\
\hline \multicolumn{2}{|c|}{ Prerequisite master's degree for doctoral program } \\
\hline No & 77.3 \\
\hline Yes & 22.7 \\
\hline \multicolumn{2}{|l|}{ Financial resources } \\
\hline \multicolumn{2}{|l|}{ Primary support } \\
\hline Fellowships/grants/scholarships & 20.8 \\
\hline Research assistantship & 46.9 \\
\hline Teaching assistantship & 22.8 \\
\hline Foreign government & 4.3 \\
\hline Other (savings, loans, internships) & 5.2 \\
\hline \multicolumn{2}{|l|}{ Full tuition remission } \\
\hline No & 31.1 \\
\hline Yes & 68.9 \\
\hline \multicolumn{2}{|l|}{ Graduate level debt } \\
\hline No loans & 31.1 \\
\hline Loans $<\$ 20,000$ & 68.9 \\
\hline Loans $>\$ 20,001$ & 9.7 \\
\hline \multicolumn{2}{|l|}{ Secondary support } \\
\hline No & 16.1 \\
\hline Yes & 83.9 \\
\hline \multicolumn{2}{|l|}{ Institutional variable } \\
\hline \multicolumn{2}{|l|}{ Carnegie classification } \\
\hline Research intensive & 4.5 \\
\hline Research extensive & 95.5 \\
\hline
\end{tabular}

Table A1 presents the descriptive statistics of the continuous variables. The average age at which international doctoral students completed their degree was 32 years. Doctorate recipients from high income countries completed at an average of 34 years old, upper-middle income 31 years old, lower-middle income 32 years old, and low income 35 years old. The mean GNI per capita was $\$ 17,867$, with high income having a mean of $\$ 38,416$, and low income having a mean of only $\$ 2,003$. This shows the level of wealth inequality among the countries of 
these students. The World Bank provided data for the wages of professionals in each country and employment rates among advanced degree holders for all economies except low-income countries. Hence, Table A2 only reports wages and unemployment rates for high income, upper-middle income, and lower-middle income economies. The table reveals that unemployment is the lowest in high income countries $(5.36 \%)$ and highest in lower-middle income countries $(14 \%)$. On the other hand, wages are highest in high income economies $(\$ 32,482)$ and lowest in lower-middle income countries $(\$ 2,388)$.

Using a conceptually grounded set of variables including the student characteristics, prior educational experience, financial support, and institutional characteristics, Table 2 presents the logistic results of labor market destination outcome with three separate models. The first model includes the four income classifications of the home country, the second includes the regions, and the third includes the economic variables from the home country. The logistic regression presents the odds ratio, which is the ratio of the probability that an event will occur to the probability that it will not happen. Factors with a greater value than 1 indicates the odds are increased, and those with odds less than 1 indicate the odds are decreased. The odds ratio can also be explained as the probability of the event occurring. The results of the first model show that the increased time to complete the doctorate significantly reduced the odds of choosing to work in the United States. The value for the odds of this variable indicates that every additional year reduced the odds of choosing to work in the United States by a factor of 0.95. Older recipients, single recipients, and recipients with dependents also had lower odds of choosing to work in the United States. Women, on the other hand, had higher odds of choosing to work in the United States. Having a U.S. bachelor's or master's degree and choosing to work in the academy rather than in the industry or other employment increased the odds of choosing to work and live in the United States by a factor of 1.64 for older recipients, 1.45 for single recipients, and 3.79 for recipients with dependents.

\section{Table 2: Logistic Regression Results of Labor Market Outcomes}

\begin{tabular}{|c|c|c|c|c|c|c|}
\hline \multirow[b]{2}{*}{ Variable } & \multicolumn{2}{|c|}{ By income } & \multicolumn{2}{|c|}{ By region } & \multicolumn{2}{|c|}{$\begin{array}{l}\text { Economic } \\
\text { controls }\end{array}$} \\
\hline & $\begin{array}{l}\text { Odds } \\
\text { ratio }\end{array}$ & $S E$ & $\begin{array}{l}\text { Odds } \\
\text { ratio }\end{array}$ & $S E$ & $\begin{array}{l}\text { Odds } \\
\text { ratio }\end{array}$ & $S E$ \\
\hline \multicolumn{7}{|l|}{ Student characteristics } \\
\hline Female & $1.09 * *$ & 0.04 & $1.12 * * *$ & 0.04 & 0.97 & 0.08 \\
\hline Age & $0.96 * * *$ & 0.04 & $0.96 * * *$ & 0.01 & $0.97 * * *$ & 0.01 \\
\hline Married & $1.58 * * *$ & 0.07 & $1.57 * * *$ & 0.07 & $1.56 * * *$ & 0.13 \\
\hline Dependents & $0.77 * * *$ & 0.04 & $0.77 * * *$ & 0.04 & $0.67 * * *$ & 0.07 \\
\hline First generation & 1.03 & 0.04 & 0.99 & 0.04 & 1.11 & 0.09 \\
\hline \multicolumn{7}{|l|}{ Prior educational experience } \\
\hline U.S. bachelor's degree & $1.64 * * *$ & 0.13 & $1.59 * * *$ & 0.12 & $2.27 * * *$ & 0.29 \\
\hline U.S. master's degree & $1.45^{* * *}$ & 0.06 & $1.49^{* * *}$ & 0.06 & $1.65^{* * *}$ & 0.14 \\
\hline Doctoral TTD completion & 1.02 & 0.02 & 1.01 & 0.02 & 1.02 & 0.04 \\
\hline Year of doctorate completion & $0.95 * * *$ & 0.02 & $0.95 * * *$ & 0.02 & 0.97 & 0.04 \\
\hline
\end{tabular}




\begin{tabular}{|c|c|c|c|c|c|c|}
\hline \multirow[b]{2}{*}{ Variable } & \multicolumn{2}{|c|}{ By income } & \multicolumn{2}{|c|}{ By region } & \multicolumn{2}{|c|}{$\begin{array}{l}\text { Economic } \\
\text { controls }\end{array}$} \\
\hline & $\begin{array}{l}\text { Odds } \\
\text { ratio }\end{array}$ & $S E$ & $\begin{array}{l}\text { Odds } \\
\text { ratio }\end{array}$ & $S E$ & $\begin{array}{l}\text { Odds } \\
\text { ratio }\end{array}$ & $S E$ \\
\hline Employer type & $3.79 * * *$ & 0.14 & $3.78 * * *$ & 0.14 & $5.29 * * *$ & 0.42 \\
\hline \multicolumn{7}{|l|}{ Academic discipline } \\
\hline Biological sciences & $1.89 * * *$ & 0.12 & $1.99 * * *$ & 0.13 & $1.59 * * *$ & 0.21 \\
\hline Engineering & $2.61 * * *$ & 0.15 & $2.67 * * *$ & 0.16 & $1.83 * * *$ & 0.24 \\
\hline Physical sciences & $2.18 * * *$ & 0.13 & $2.26 * * *$ & 0.13 & $1.87 * * *$ & 0.23 \\
\hline Humanities & 1.19 & 0.10 & 1.17 & 0.10 & 1.06 & 0.17 \\
\hline Education & $1.32 * * *$ & 0.13 & $1.35 * * *$ & 0.13 & 1.45 & 0.31 \\
\hline Business management & $0.67 * *$ & 0.12 & $0.66^{* *}$ & 0.12 & 0.87 & 0.37 \\
\hline \multicolumn{7}{|l|}{ Financial support } \\
\hline Secondary support & $1.33 * * *$ & 0.07 & $1.37 * * *$ & 0.07 & $1.33 * *$ & 0.17 \\
\hline Fellowship/grants/scholarships & $0.71 * * *$ & 0.06 & $0.73 * * *$ & 0.06 & $0.55 * * *$ & 0.09 \\
\hline Research assistantship & $1.39 * * *$ & 0.11 & $1.46 * * *$ & 0.12 & 0.92 & 0.17 \\
\hline Teaching assistantship & 1.02 & 0.08 & 1.08 & 0.09 & 0.83 & 0.15 \\
\hline Foreign government & $0.17 * * *$ & 0.02 & $0.17 * * *$ & 0.02 & $0.15^{* * *}$ & 0.03 \\
\hline Full tuition remission & $1.38 * * *$ & 0.06 & $1.38 * * *$ & 0.06 & $1.36 * * *$ & 0.11 \\
\hline $\begin{array}{l}\text { Graduate debt }<\$ 20,000 \\
\text { (Reference: No debt) }\end{array}$ & 0.99 & 0.05 & 1.01 & 0.06 & 1.03 & 0.11 \\
\hline Graduate debt $>\$ 20,001$ & 0.91 & 0.05 & 0.91 & 0.05 & 0.89 & 0.11 \\
\hline \multicolumn{7}{|l|}{ Institutional characteristics } \\
\hline Research extensive & 0.88 & 0.08 & 0.87 & 0.079 & 1.242 & 0.232 \\
\hline Logged U.S. faculty salaries & $4.79 * * *$ & 1.51 & $5.04 * * *$ & 1.59 & $4.42 * *$ & 3.19 \\
\hline \multicolumn{7}{|l|}{ By income } \\
\hline High income & $0.61 * * *$ & 0.03 & - & - & - & - \\
\hline Low income & 1.19 & 0.15 & - & - & - & - \\
\hline Lower-middle income & $1.23 * * *$ & 0.06 & - & - & - & - \\
\hline \multicolumn{7}{|l|}{ By region } \\
\hline East Asia and Pacific & - & - & $1.18 * * *$ & 0.07 & - & - \\
\hline Latin America \& the Caribbean & - & - & 0.87 & 0.07 & - & - \\
\hline Middle East \& North Africa & - & - & $1.51 * * *$ & 0.12 & - & - \\
\hline North America & - & - & 0.96 & 0.09 & - & - \\
\hline South Asia & - & - & $2.01 * * *$ & 0.15 & - & - \\
\hline Sub-Saharan Africa & - & - & $1.47 * * *$ & 0.16 & - & - \\
\hline \multicolumn{7}{|l|}{ Economic factors } \\
\hline Logged GNI per capita & - & - & - & - & $0.83 * *$ & 0.13 \\
\hline Logged wages in home country & - & - & - & - & $1.34 * * *$ & 0.13 \\
\hline Unemployment rates in home & - & - & - & - & $1.05 * * *$ & 0.01 \\
\hline$p>\chi^{2}$ & 0.05 & & 0.11 & & 0.05 & \\
\hline
\end{tabular}

Note. GNI $=$ gross national income.

Compared with recipients in the social sciences, those in the biological sciences, engineering, physical sciences, and education were more likely to choose to work in the United States. Doctoral recipients from high income countries had lower odds than recipients of upper-middle income countries of choosing to work in the United States. On the other hand, recipients from lower- 
middle income countries were more likely to choose to remain in the United States. In the model controlling for region, we found all the same significance and direction for all variables except for the year of doctorate completion being statistically insignificant. Compared with recipients from Europe and Central Asia region, recipients from the Middle East and North Africa, South Asia, and SubSaharan Africa had greater odds of choosing to work in the United States.

With regards to sources of financial support, we found that holding a research assistantship during doctoral studies increased the odds of choosing to work in the United States. Also, having a secondary source of financial support also increased the odds of remaining in the United States. However, students who were supported by fellowships/grants and by their home country governments had significantly reduced odds of choosing to work in the United States. The final model controlled for economic factors from the home country but did not include students from low-income countries because data for wages and unemployment was unavailable. Just like in the first model, being an older student and having dependents decreased the likelihood of choosing to work and live in the United States. Married students had significantly higher odds of choosing to work in the United States. Across the board, higher U.S. faculty salaries significantly increased the odds of choosing to work in the United States. Among the economic indicators, we found that higher GNI per capita in the home country is associated with a decreased odd of choosing to work in the United States. Higher wages and higher unemployment rates increased the likelihood of choosing the U.S. labor market among students from higher income, upper-middle, and lower-middle income countries.

\section{High Income Countries}

Table 3 presents the logistic results of the predictors of labor market destination outcomes for each home country income classification. Those who were from high income countries who were older doctorate recipients or who had dependents were less likely to remain in the United States after graduation. Gender is not statistically significant with regard to the decision to stay or return home for recipients from high income countries. Recipients with longer time to doctoral degree completion and those with a U.S. bachelor's and master's degree were more likely to choose to work in the United States than their counterparts who obtained those degrees in foreign countries. Those who chose to work in the academy were also more likely to choose to remain in the United States. This is true for all economies. Among the academic disciplines, all the fields except for business are more likely than those in the social sciences to choose to work in the United States. The humanities discipline is not statistically significant. Among financial sources, recipients who were primarily funded through research assistantships and full tuition remissions were more likely to choose to work in the United States. The same is true for those who had secondary support to finance their degrees. On the other hand, recipients who received foreign government funds to finance their degree were less likely to remain in the United States after 
graduation. Attending a research extensive institution also increased the likelihood of choosing to work in the United States.

Table 3: Predictors of Labor Market Destination Outcomes Across Home Country Income Classifications (Logistic Regression)

\begin{tabular}{|c|c|c|c|c|c|c|c|c|c|c|}
\hline \multirow[b]{2}{*}{ Variable } & \multicolumn{2}{|c|}{ Full model } & \multicolumn{2}{|c|}{ High income } & \multicolumn{2}{|c|}{$\begin{array}{l}\text { Upper-middle } \\
\text { income }\end{array}$} & \multicolumn{2}{|c|}{$\begin{array}{l}\text { Lower-middle } \\
\text { income }\end{array}$} & \multicolumn{2}{|c|}{ Low income } \\
\hline & $\begin{array}{l}\text { Odds } \\
\text { ratio }\end{array}$ & $S E$ & $\begin{array}{l}\text { Odds } \\
\text { ratio }\end{array}$ & $S E$ & $\begin{array}{l}\text { Odds } \\
\text { ratio }\end{array}$ & $S E$ & $\begin{array}{l}\text { Odds } \\
\text { ratio }\end{array}$ & $S E$ & Odds ratio & $S E$ \\
\hline \multicolumn{11}{|l|}{ Student characteristics } \\
\hline Female & $1.09 * *$ & 0.04 & 1.12 & 0.08 & 1.11 & 0.06 & 0.95 & 0.09 & 1.08 & 0.38 \\
\hline Age & $0.96 * * *$ & 0.01 & $0.98 * *$ & 0.01 & $0.97 * * *$ & 0.01 & $0.93 * * *$ & 0.01 & 0.95 & 0.03 \\
\hline Married & $1.58 * * *$ & 0.06 & $1.49 * * *$ & 0.12 & $1.73 * * *$ & 0.10 & $1.35 * * *$ & 0.14 & 1.18 & 0.40 \\
\hline Dependents & $0.79 * * *$ & 0.04 & $0.71 * * *$ & 0.06 & $0.87 * *$ & 0.06 & $0.73 * * *$ & 0.08 & 0.62 & 0.20 \\
\hline First generation & 1.04 & 0.04 & 0.99 & 0.07 & 1.07 & 0.06 & 1.05 & 0.11 & 1.16 & 0.36 \\
\hline \multicolumn{11}{|c|}{ Prior educational experience } \\
\hline U.S. bachelor's degree & $1.53 * * *$ & 0.11 & $2.17 * * *$ & 0.25 & $1.26^{* * *}$ & 0.16 & 1.38 & 0.28 & 1.84 & 0.98 \\
\hline U.S. master's degree & $1.45 * * *$ & 0.05 & $1.30 * * *$ & 0.10 & $1.32 * * *$ & 0.07 & $1.99 * * *$ & 0.19 & 1.88 & 0.54 \\
\hline $\begin{array}{l}\text { Doctoral time-to-degree } \\
\text { completion }\end{array}$ & $1.05 * * *$ & 0.01 & $1.05 * *$ & 0.02 & $1.05^{* *}$ & 0.02 & 1.05 & 0.03 & 0.98 & 0.09 \\
\hline Year of doctorate completion & $1.09 * *$ & 0.04 & 1.10 & 0.07 & 1.02 & 0.05 & $1.21 * *$ & 0.11 & 1.20 & 0.33 \\
\hline Employer type & $3.86 * * *$ & 0.14 & $6.76 * * *$ & 0.48 & $2.93 * * *$ & 0.16 & $2.86 * * *$ & 0.27 & $2.73 * * *$ & 0.87 \\
\hline \multicolumn{11}{|l|}{ Academic discipline } \\
\hline Biological Sciences & $2.23 * * *$ & 0.14 & $2.22 * * *$ & 0.28 & $1.69^{* * *}$ & 0.16 & $2.80 * * *$ & 0.41 & 0.77 & 0.32 \\
\hline Engineering & $2.98 * * *$ & 0.17 & $2.08 * * *$ & 0.23 & $2.90 * * *$ & 0.24 & $2.55 * * *$ & 0.36 & 0.80 & 0.37 \\
\hline Physical Sciences & $2.43 * * *$ & 0.14 & $1.76 * * *$ & 0.19 & $2.54 * * *$ & 0.22 & $2.02 * * *$ & 0.29 & 2.04 & 0.92 \\
\hline Humanities & 1.06 & 0.09 & 1.12 & 0.15 & $1.02 * * *$ & 0.15 & 1.20 & 0.33 & 1.26 & 1.01 \\
\hline Education & $1.32 * * *$ & 0.12 & $1.59 * * *$ & 0.25 & 1.22 & 0.18 & 1.23 & 0.30 & 0.25 & 0.17 \\
\hline Business Management & 0.71 & 0.12 & 0.53 & 0.18 & 0.75 & 0.20 & 1.15 & 0.53 & - & - \\
\hline \multicolumn{11}{|l|}{ Financial support } \\
\hline Secondary support & $1.32 * * *$ & 0.07 & $1.45 * * *$ & 0.14 & $1.19^{* *}$ & 0.09 & $1.53 * * *$ & 0.18 & 1.63 & 0.51 \\
\hline $\begin{array}{l}\text { Fellowship/grants/ } \\
\text { scholarships }\end{array}$ & $0.76^{* * *}$ & 0.06 & 1.08 & 0.13 & $0.70^{* *}$ & 0.10 & $0.32 * * *$ & 0.07 & 0.41 & 0.24 \\
\hline Research assistantship & $1.53 * * *$ & 0.12 & $1.66 * * *$ & 0.22 & $1.49 * * *$ & 0.20 & 0.72 & 0.16 & 1.42 & 0.87 \\
\hline Teaching assistantship & 1.15 & 0.09 & 1.23 & 0.16 & 1.04 & 0.14 & $0.61 * *$ & 0.14 & 1.11 & 0.67 \\
\hline Foreign government & $0.17 * * *$ & 0.02 & $0.24 * * *$ & 0.04 & $0.16 * * *$ & 0.02 & $0.14 * * *$ & 0.04 & $0.30 * * *$ & 0.78 \\
\hline Full tuition remission & $1.38 * * *$ & 0.05 & $1.40 * * *$ & 0.10 & $1.38 * * *$ & 0.08 & $1.26 * *$ & 0.12 & 1.55 & 0.43 \\
\hline $\begin{array}{l}\text { Graduate debt }<\$ 20,000 \text { (Ref: } \\
\text { No debt) }\end{array}$ & 1.04 & 0.06 & 1.08 & 0.11 & 0.88 & 0.07 & 0.99 & 0.11 & $2.52 * *$ & 0.92 \\
\hline Graduate debt $>\$ 20,001$ & $0.88 * *$ & 0.05 & 0.87 & 0.09 & 0.86 & 0.08 & 0.98 & 0.16 & $2.52 * * *$ & 1.34 \\
\hline \multicolumn{11}{|l|}{ Institutional characteristics } \\
\hline Research extensive & $0.81 * *$ & 0.07 & 1.23 & 0.20 & 0.78 & 0.12 & 0.89 & 0.15 & 0.49 & 0.27 \\
\hline U.S. faculty salaries & $4.66 * * *$ & 1.42 & $6.12 * * *$ & 3.70 & $4.05 * * *$ & 1.79 & 3.15 & 2.38 & 0.86 & 2.67 \\
\hline$p>\chi^{2}$ & \multicolumn{2}{|c|}{0.05} & \multicolumn{2}{|c|}{0.17} & \multicolumn{2}{|c|}{0.00} & \multicolumn{2}{|c|}{0.06} & \multicolumn{2}{|l|}{0.00} \\
\hline
\end{tabular}

\section{Upper-Middle Income Countries}

For recipients from upper-middle income countries, age had a statistically significant effect. We found that older recipients, single recipients, and those with dependents are less likely to remain in the United States after graduation. Just like high income countries, having a U.S. bachelor's or master's degree and longer time to doctoral degree completion statistically increased the likelihood of remaining in the United States after graduation. Among the academic disciplines, only recipients from the STEM fields were more likely to choose to work in the United States after graduation. For upper-middle income recipients, funding through fellowships or scholarships and foreign governments sponsorship reduced the likelihood of remaining in the United States after graduation. On the 
other hand, research assistantships, secondary support, and full tuition remissions increased the likelihood of remaining in the United States postgraduation.

\section{Lower-Middle Income Countries}

We found that older recipients, single recipients, and recipients with dependents were less likely to choose to remain in the United States postgraduation. For this group of recipients, having a U.S. master's degree statistically increased the likelihood of choosing to stay in the United States for employment but having a U.S. bachelor's degree was not statistically significant. Similar to recipients from upper-middle income countries, we found that only STEM recipients were more likely to choose to work in the United States. For this group, having a research assistantship was not statistically significant in terms of labor market destination choices. We found that recipients who had secondary support and full tuition remission during their degree were more likely to remain in the United States. However, just like for other economies, recipients funded by a foreign government were less likely to remain in the United States.

\section{Low Income Countries}

For low-income countries, we found less statistical significance. There were very few statistical differences among students from low-income countries. Among the demographic and academic disciplines, the students did not statistically differ from one another in terms of the decision to stay in the United States or return to their home countries. This implies that the students in other academic disciplines were not statistically more or less likely to choose to work in the United States than those in the social sciences. The only sources of financial support that were statistically significant were foreign government and graduate debt. Just like their counterparts from richer economies, foreign government support reduced the odds of choosing to work in the United States after graduation while graduate debt significantly increased the odds of choosing to remain in the United States compared with others with no debt. The effect of debt over $\$ 20,000$ had the largest magnitude among students from low-income countries.

\section{HLM Analysis}

To understand the effects at both levels - individual and country-we conducted the HLM analysis, and the results are presented in Table 4. The results of the HLM found that country of origin had a significant effect on the labor market choices for international doctorate recipients. After controlling for country of origin, we found that older recipients, single recipients, and those with dependents were less likely to choose to work in the United States. Having a U.S. bachelor's or master's degree increased the likelihood of choosing to work in the United States, and the magnitude was even larger for those who obtained their bachelor's degree in the United States. Those who chose to work in the academy (universities and colleges) rather than in the industry or other employment 
opportunities were more likely to choose to work in the United States. Recipients who received research assistantship and full tuition remission were more likely to choose to remain in the United States for work. The same is true for those who supplemented their primary sources of funding with secondary supports. However, doctoral recipients who were funded by foreign government or scholarships and grants were less likely to remain in the United States after graduation. We conducted separate analysis by academic field. In the STEM fields, we found that holding a U.S, master's degree, longer time to degree completion, and employer type significantly increased the odds of choosing to work in the United States. In engineering, research and teaching assistantships increased the odds of choosing to work in the United States, while foreign government sponsorship reduced the odds of remaining in the United States. Across all disciplines, foreign government support reduced the odds of the recipient choosing to work in the United States and choosing to work in a university/college increased the odds of remaining in the United States.

Table 4: Hierarchical Linear Modeling Results of International Doctoral Recipients Labor Market Destination Choices

\begin{tabular}{lll}
\hline Variable & Odds ratio & $S E$ \\
\hline Country-level variables & & \\
\hline Country intercept & $0.41^{* * *}$ & 0.43 \\
Logged gross national income per capita & $0.03^{* * *}$ & 0.00 \\
\hline Student level variables & & \\
\hline Female & 1.05 & 0.04 \\
Age & $0.97^{* * *}$ & 0.00 \\
Married & $1.43^{* * *}$ & 0.06 \\
Dependents & $0.83^{* * *}$ & 0.04 \\
First generation & 1.04 & 0.04 \\
U.S. bachelor's degree & $2.22^{* * *}$ & 0.17 \\
U.S. master's degree & $1.41^{* * *}$ & 0.05 \\
Doctoral time-to-degree completion & $1.04^{* * * *}$ & 0.01 \\
Year of doctorate completion & 1.04 & 0.04 \\
Employer type & $3.08^{* * *}$ & 0.01 \\
Secondary support & $1.18^{* * *}$ & 0.06 \\
Fellowship/grants/scholarships & $0.83^{* *}$ & 0.06 \\
Research assistantship & $1.75^{* * *}$ & 0.14 \\
Teaching assistantship & 1.09 & 0.09 \\
Foreign government & $0.30^{* * *}$ & 0.03 \\
Full tuition remission & $1.19^{* * *}$ & 0.05 \\
Graduate debt $<\$ 20,000$ & 0.98 & 0.05 \\
Graduate debt $>\$ 20,001$ & 0.97 & 0.06 \\
Research extensive & 1.04 & 0.09 \\
\hline
\end{tabular}




\section{DISCUSSION}

The purpose of this study was to examine the effects of financial aid and home country macroeconomic indicators on international doctoral students' labor market destination choices. By conducting logistic regression analysis and HLM analysis, it was possible to compare the unique and common factors impacting international doctoral recipients in the United States across regions and economies of the home country. Previous studies on international doctoral recipients have not studied the relationship between individual characteristics, educational experiences, or financial aid sources and destination choices. Hence, this study was a novel attempt to investigate these relationships and offer possible explanations based on the results.

The results from this study yield interesting findings of how economic factors in the home country and financial aid sources are related to the labor market destination choices of international doctoral recipients in the United States. Furthermore, the results support previous research on brain migration and offer additional insights on what factors are important to consider for different home countries by region and level of development of the home country.

Single students and those with dependents are more likely to return to their home countries. Single recipients, particularly those from collectivists cultures, may feel that their chances of transitioning into marriage and family life are low if they remain in the United States, and recipients with dependents, born prior to their arrival in the United States, may face immigration challenges for their children, as well as adjustment and other psychological issues related to relocating dependents.

The human capital theory was supported. This study confirmed higher extrinsic costs will lead the recipient to seek higher benefits. We found that recipients who invested more in the U.S. system in form of tuition, fees, and general living expenses to obtain a U.S. bachelor's or master's degree were more likely to choose to work in the United States. Doctoral recipients who have spent a long time in the United States may seek to recoup some of their investment in the system. This is true across all economies and particularly true for low-income students who are 2 times more likely to choose to work in the United States compared with their counterparts with foreign education. It is also plausible that spending a long time in the United States implies that the recipients have more ties, relationships, and connections in the United States, making them less willing to return to their home countries. Employer type significantly increased the odds of choosing to work in the United States across all models. This is likely due to $\mathrm{H}-1 \mathrm{~B}$ laws and regulations in the United States. American universities and colleges are not subject to the same H-1B lottery caps imposed on other labor market employers. Hence, doctoral recipients who have a desire to pursue academic careers are more likely to choose to work in the United States than their peers who desire to work in the industry or in nonacademic environments. It is possible that the odds are higher for university jobs because American universities have more sophisticated research facilities and offer higher standard of living and promotion opportunities than what is available in the home countries of many 
doctoral recipients. Many U.S. companies are located outside of the United States and can employ international students to work back home, but few U.S. universities have campuses abroad.

As expected, recipients from the STEM fields were more likely to choose to work in the United States and had greater odds than any other academic disciplines. This is true for all economies except for low-income countries, where only the physical sciences were significantly more likely than the social sciences to choose to work in the United States. H-1B visa immigration rules, which favor STEM recipients, may be largely responsible for this. In addition, students from upper-middle and lower-middle income countries (who make up the bulk of the STEM fields) may not have access to the same level of technological sophistication and scientific equipment in their home countries. For such recipients, returning to their home may imply that they would be unable to fully utilize the advanced knowledge and skills that they have acquired in the U.S. system.

The sources of financial support were also related to labor market destination choices for international doctoral recipients. Here, we found that U.S. sources of financial support, including research assistantships, teaching assistantships, and full tuition remissions, increase the likelihood of remaining in the United States to work after graduation. However, foreign sources, including foreign government aid, scholarships, and fellowships, reduced the likelihood of remaining in the United States to work. This is plausible for a couple of reasons. First, most foreign support is tied to commitments after graduation, including serving the home country government or sponsoring entity in an agreed capacity after obtaining the degree. In some countries, students are required to submit a proposed dissertation study and include how results from the study will be used in developing the country or advancing a foreign company. Secondly, most foreign sources of support typically cover all the student expenses while in the host country, and hence, the student may not feel the need to recoup their investment from the U.S. system after graduation. Finally, foreign aid, particularly from the government, may build or further foster a sense of patriotism in the recipient, causing them to be more likely to return to their home country. In the sub analysis, we found that foreign aid reduced the likelihood for remaining in the United States for all economies except low-income countries. Harsher economic conditions combined with unstable political climates that plague these countries may be responsible for this result. For low-income countries, we found that debt significantly increased the odds of remaining in the United States after graduation by more than 3 times for those who had debt over $\$ 20,000$. Lower wages in these countries may imply that doctoral recipients may be unable to repay such loans if they return home.

The more interesting findings in this study involve the effects of the economic factors on labor market destination choices. The push-pull model was supported. Home country GNI per capita was found to be an important factor related to student choices, a finding that is consistent with Agbonlahor (2019) and the Szelenyi's (2006) study on migratory decision making. Szelenyi (2006) found that students from less developed countries were more likely to choose to transition into the U.S. labor force. This study found that higher GNI per capita was 
associated with decreased likelihood of remaining in the United States. It also found that higher unemployment rates in the home country significantly increased the likelihood of choosing to remain in the United States. A conflicting result is that higher wages in the home country were also related to increased likelihood of remaining in the United States. On the other hand, fields with higher U.S. faculty salaries significantly increase the likelihood of remaining in the United States. Compared with upper-middle income students, students from high income countries were less likely to remain in the United States after graduation, while recipients from low-middle- and low-income countries were more likely to remain in the United States after graduation. Compared with recipients from Europe and Central Asia, recipients from the Middle East and North Africa, South Asia, and Sub-Saharan Africa were more likely to choose to remain in the United States after graduation. This conclusively points to the economic conditions and opportunities for upward mobility available in those economies and regions. The results support the push-pull model, in that doctoral recipients in the United States make comparisons between economic conditions of their home countries and the United States, and the larger the difference, the larger the size of migration flow (Todaro, 1976).

\section{Limitations of the Study}

A limitation of this study is that it does not consider the role of mentoring in international doctoral students' labor market outcomes. Doctoral advisors play an important role because they are the primary socialization agent at the doctoral level and the principal connection between the student and the department (Girves \& Wemmerus, 1988; Golde, 2005; Tinto, 1975; Weidman et al., 2001). International student literature has also examined the role of advisors in the socialization of students from foreign cultures. Jindal-Snape and Ingram (2013) discussed the importance of advisors on the adjustment of international doctoral students in developing supportive networks for student success. Thus, the relationship the advisor holds with the advisee may directly impact the students' socialization, the quality of their doctoral experiences, and their postgraduate options through the provision of opportunities to attend and present at conferences, participate in research projects, and co-author publications.

Secondly, because this study utilized existing data, perceptions of international students about the quality of their international education are not available. The dataset does not include other personal or institutional factors that could impact on the ability of the individual to access a U.S. position such as the quality of career services of the university, the number of publications or experience the student has, the faculty rank of the advisor, or marriage to a U.S. citizen. These factors could influence the ability of the student to secure a U.S. job more than some of the explanatory variables included in this study. It is also noteworthy that because the SED is collected when the students have just graduated, a number of the students may not have firm job plans and hence, the analysis is limited to those who know their job placement and location at the time of the survey. 


\section{Implications}

The study reveals a need to develop career services support for international students that are tailored to their unique concerns and vocational challenges. Besides providing services such as resume and cover letter editing, university career services need to position international recipients to make a successful transition into the labor market. When international students seek to work in the United States, they need to go through rigorous immigration guidelines and bureaucratic procedures (Shih \& Brown, 2000). Students who want to return to their home countries also need guidance as they return to a system that could have changed dramatically since they relocated to the United States. The results from the study found that international recipients from low-income countries with debt of more than $\$ 20,000$ were more likely to choose to remain in the United States. Since it is not possible for all these students to transition into the U.S. labor market because of limited H-1B visas, university career services tailored to the global economy would be beneficial in assisting these students to transition to other highincome countries in need of their talent or skill. We recommend that university career services hire well-trained specialists tasked with the responsibility of understanding different countries' employment needs, immigration requirements, and opportunities by academic field and job roles. This could be posted on the university career services webpage and updated regularly. For example, career services could have a page where students could search for faculty positions in Europe and whether non-European Union citizens could apply for such positions. Similarly, positions in Sub-Saharan Africa, the Middle East and Africa, and all other regions could be included. This might ultimately yield to a more uniform distribution of talent and skill and reduce wage inequalities as a result of asymmetry of information.

The international student literature has also examined the role of advisors in the socialization of students from foreign cultures. International students have reported changing their faculty advisors because of lack of intercultural competence, reluctance to supervise a topic, racial discrimination, and language barriers (Wei et al., 2012). U.S. faculty members may be more reluctant to supervise a topic if the research is on a foreign country that they know little or nothing about. This has led many international students to choose topics within their advisors' expertise and interest. The problem with this is that most students will then be researching an issue important in the United States but may not have practical implications in their home country. If international students continue to develop thesis research that cannot be applied to local or national issues in their country, then the likelihood of returning home will remain low. On the other hand, recipients with foreign aid are supported by their government to research a particular issue and provide results or policy implications that can be applied to their national context.

Based on this finding and the extant literature on international doctoral students, we recommend that academic departments and the institutions work on internationalizing the curriculum so that international students can develop solutions to their home country's specific needs while training with more 
sophisticated technology and accessing more advanced knowledge in the United States. An internationalized curriculum and co-curriculum ensure that both domestic and international students are exposed to international perspectives and build global competence. An internationalized curriculum will address global issues, reinforce international elements of the curriculum, develop solutions to problems in countries outside the United States, facilitate discussion and interaction among students of different backgrounds, and support the integration and success of international students.

The study's framework was derived from the human capital theory and the push-pull model to explain international doctoral recipients' labor market destination choices. Prior to this study, international students have been examined along with domestic students, and thus, the unique factors in their countries of origin that impact their outcomes have not been considered. The new framework developed in this study explains how student characteristics, in addition to economic factors in the home country (push factors) and economic factors in the United States (pull factors), intersect to affect international doctoral students' choices and outcomes.

Finally, longitudinal data that tracks a sample of international doctoral recipients both in the United States and when they return home should be developed. A limitation of this study is that the international doctoral recipients' destination is for 1 year after graduation. While international students are legally authorized to work for any employer in the United States through the Optional Practical Training, most of them will eventually require their employers to sponsor their H-1B visas in order to remain in the United States. Hence, several of the students from this study who chose to remain in the United States will eventually have to leave the United States if they are unable to secure a position in which the employer is willing to file their H-1B visa and demonstrate that a United States citizen does not have the required skill for the job or the job search has been unable to fill the position domestically. Future studies need to use longitudinal data to study actual and long-term labor market destination outcomes of international doctoral recipients. This will provide a richer and deeper analysis of their transitions, career development, and life outcomes.

\section{Note}

Appendices for this article can be found on the JIS website at https://www.ojed.org/index.php/jis

\section{REFERENCES}

Acemoglu, D., Gallego, F. A., \& Robinson, J. A. (2015). Institutions, human capital, and development. Annual Review of Economics, 6(1), 875-912. Agbonlahor, O. (2019). The impact of financial aid factors and home country economic conditions on international doctoral students' time-to-degree 
completion and labor market destination choices. (Unpublished dissertation, Central Michigan University).

Becker, G. S. (1962). Investment in human capital: A theoretical analysis. The Journal of Political Economy, 70(5), 9-49.

Bhagwati, J., \& Dellalfar, W. (1973). The brain drain and income taxation. World Development, 1(1-2), 94-101.

Bound, J., Khanna, G., \& Morales, N. (2017). Understanding the economic impact of the H1B visa on the U.S. NBER Working Paper Series. https://www.nber.org/papers/w23153.pdf

Bryła, P. (2019). International student mobility and subsequent migration: the case of Poland. Studies in Higher Education, 44(8), 1386-1399.

Das, M. S. (1969). Effects of foreign students' attitudes towards returning to the country of origin on the national loss of professional skills. Oklahoma University Press.

Desjardins, L. (2012, July). Profile and labor market outcomes of dcotoral graduates from Ontario universities. Culture, Tourism, and Center for Education Statistics: Research Paper Series, 98, 1-107.

Finn, G. (2001). Stay rates of foreign doctorate recipients from U.S. institutions, 1999. Oak Ridge Institute for Science and Education.

Girves, J. E., \& Wemmerus, V. (1988). Developing models of graduate student degree progress. The Journal of Higher Education, 59(2), 163-189.

Glaser, W. (1978). The brain drain: Emigration and return. Pergamon.

Golde, C. M. (2005). The role of the department and discipline in doctoral student attrition: Lessons from four departments. The Journal of Higher Education, 76(6), 669-700.

Haque, N., \& Kim, S.-J. (1995). Human capital flight: Impact of migration on income and growth. IMF Staff Papers, 42(3), 577-607.

Hazen, H. D., \& Alberts, H. C. (2006). Visitors or immigrants? International students in the U.S. Population, Space, and Place, 12(1), 201-216.

Heck, R. H., \& Thomas, S. L. (2000). An introduction to multilevel modelling techniques. Lawrence Erlbaum.

Jindal-Snape, D., \& Ingram, R. (2013). Understanding and supporting triple transitions of international doctoral students: ELT and SuReCom Models. Journal of Perspectives in Applied Academic Parctice, 1(1), 17-24.

Johnson, J., \& Regets, M. C. (1998, June 22). International mobility of scientists and engineers to the United States: Brain drain or brain circulation? [SRS Issue Brief]. National Science Foundation.

Massey, D., Arango, J., Hugo, G., Kouaouci, A., Pellegrino, A., \& Taylor, J. (1993). An evaluation of international migration theory: The North American Case. Population and Development Review, 20(4), 699-751.

Mazzarol, T., \& Soutar, G. N. (2002). "Push-pull" factors influencing international student destination choice. International Journal of Education Management, 16(2), 82-90.

Migration Policy Institute. (2018, May 9). International students in the United States. https://www.migrationpolicy.org/article/international-studentsunited-states 
Sage, J., Evandrou, M., \& Falkingham, J. (2013). Onwards or homewards? Complex graduate migration pathways, well-being, and the 'parental safety net'. Population, Space and Place, 19(6), 738-755.

Shih, S.-F., \& Brown, C. (2000). Taiwanese International students: Acculturation level and vocational identity. Journal of Career Development, 27, 35-47. doi:https://doi.org/10.1023/A:1007796509562

Szelenyi, K. (2006). Students without borders? Migratory decision-making among international graduate students in the U.S. Knowledge, Technology, and Policy, 19(3), 64-86.

Thomas, S., \& Heck, R. (2001). Analysis of large sclae secondary data in higher education research: Potential perils associated with complex sampling designs. Research in Higher Education, 142(5), 517-540.

Tinto, V. (1975). Dropouts from higher education: A theoretical synthesis of recent literature. Review of Educational Research, 45, 89-125.

Todaro, M. (1976). A model of labor migration and urban unemployment in less developed countries. The American Economic Review, 59(1), 138-148.

Wei, M., Liao, K. Y.-H., Heppner, P. P., Chao, R. C.-L., \& Ku, T.-Y. (2012). Forbearance coping, identification with heritage culture, acculturative stress, and psychological distress among Chinese international students. Journal of Counseling Psychology, 59(1), 97-106. https://doi.org/10.1037/a0025473

Weidman, J. C., Twale, D. J., \& Stein, E. L. (2001). Socialization of graduate and professional students in higher education: A perilous passage? ASHE-ERIC Higher Education Report, 28(3).

Wong, G. Y., \& Mason, W. (1995). The hierarchy logistic model for multilevel analysis. Journal of the American Statistical Association, 80(391), 513-524.

The World Bank. (2017). World Bank country and lending groups. https://datahelpdesk.worldbank.org/knowledgebase/articles/906519-worldbank-country-and-lending-groups

Yang, E., Wong, C., Hwang, M., \& Heppner, M. J. (2002). Widening our global view: The development of career counselling services for international students. Journal of Career Development, 28(3), 203-213.

OSASOHAN AGBONLAHOR, $\mathrm{PhD}$, is a postdoctoral research associate in the department of Leadership, Research, and Foundations at the University of Colorado - Colorado Springs. Her intellectual interests are in the fields of the economics of education, international education, and higher education policy. Her research focuses on labor market outcomes of higher education, the career trajectories of international doctoral recipients and the participation of underrepresented minorities in STEM fields. Email: oagbonla@uccs.edu

FRIM AMPAW, EdD, is Professor of Higher Education in the Department of Educational Leadership at Central Michigan University. Her research focuses on labor market implications of higher education, persistence of women and underrepresented minorities in STEM fields and the transition and persistence of 
students through the various levels of higher education. Email: ampaw1fd@cmich.edu 